\title{
Sodium bicarbonate ingestion improves Yo-Yo intermittent recovery test I performance: a randomized crossover trial
}

This article was published in the following Dove Press journal:

Nutrition and Dietary Supplements

28 April 2017

Number of times this article has been viewed

\section{Helen Dixon' \\ Catherine E Baker ${ }^{2}$ \\ Julien S Baker ${ }^{3}$ \\ Susan Dewhurst ${ }^{4}$ \\ Lawrence D Hayes ${ }^{4}$}

'School of Human Sciences, London Metropolitan University, London, ${ }^{2}$ English Institute of Sport, Bisham Abbey National Sports Center, Buckinghamshire, ${ }^{3}$ Institute of Clinical Exercise and Health Science, University of the West of Scotland, Hamilton, ${ }^{4}$ Department of Medical and Sport Sciences, University of Cumbria, Lancaster, UK
Correspondence: Lawrence D Hayes Department of Medical and Sport Sciences, University of Cumbria, Bowerham Road, Lancaster, LAI 3JD, UK Email Lawrence.Hayes@Cumbria.ac.uk
Abstract: This study investigated the effect of sodium bicarbonate $\left(\mathrm{NaHCO}_{3}^{-}\right)$ingestion on the Yo-Yo intermittent recovery test 1 (IR1). We tested the hypothesis that acute ingestion of $\mathrm{NaHCO}_{3}{ }^{-}$would increase blood lactate concentrations [BLa], enhance performance, and reduce rating of perceived exertion (RPE) in the Yo-Yo IR1. Eight recreationally active males $(\mathrm{N}=8$, age: $26 \pm 4 \mathrm{yr}$, height: $178 \pm 6 \mathrm{~cm}$, body mass: $82 \pm 10 \mathrm{~kg}$ ) participated in the Yo-Yo IR1 on two separate occasions, separated by $1 \mathrm{wk}$, in a randomized crossover design. Following familiarization, during seated rest, participants' pretest [BLa] was taken, and participants then consumed either a placebo of $0.3 \mathrm{~g} \cdot \mathrm{kg}^{-1}$ body weight sodium chloride or $0.3 \mathrm{~g} \cdot \mathrm{kg}^{-1}$ body weight $\mathrm{NaHCO}_{3}^{-}$. Sixty minutes postingestion, a standardized warm-up preceded the Yo-Yo IR1. Upon completion, postexercise [BLa] $\left(\mathrm{mmol} \cdot \mathrm{L}^{-1}\right)$, RPE (arbitrary units) and Yo-Yo IR1 time to fatigue (s) were recorded. Paired $t$-test revealed a small but significant improvement in Yo-Yo IR1 performance under the $\mathrm{NaHCO}_{3}^{-}$condition $(610 \pm 267 \mathrm{sec})$, compared to the placebo condition $(556 \pm 259$ sec; $p=0.01$; Cohen's $d=0.20)$. [BLa] increased more under the $\mathrm{NaHCO}_{3}{ }^{-}$condition $(1.6 \pm 0.7$ to $17.5 \pm 5.2 \mathrm{mmol} \cdot \mathrm{L}^{-1} ; p<0.001$; Cohen's $\left.d=4.29\right)$, compared to the placebo condition $(2.0 \pm 0.7$ to $11.5 \pm 5.0 \mathrm{mmol} \cdot \mathrm{L}^{-1} ; p=0.001$; Cohen's $\left.d=2.66\right)$. Postexercise RPE was not significantly different between conditions. The results of this study suggest that acute $\mathrm{NaHCO}_{3}{ }^{-}$ingestion improves Yo-Yo IR1 performance without altering RPE, likely through an increased lactate efflux, demonstrated by increased [BLa].

Keywords: alkalosis, anaerobic, blood lactate, ergogenic aid, performance, repeated sprints

\section{Introduction}

Muscular performance declines during prolonged and intense activity, with changes in metabolites contributing to reductions in force production, muscle shortening velocity, and prolongation of relaxation. ${ }^{1}$ Mechanisms such as acid excretion via the kidneys, hyperventilation, and blood bicarbonate $\left(\mathrm{HCO}_{3}^{-}\right)$operate to offset increased production and release of hydrogen $\left(\mathrm{H}^{+}\right)$during times of accelerated metabolism. ${ }^{2}$ Changes in muscle $\mathrm{pH}$ have been suggested to play a critical role in fatigue, ${ }^{3}$ while reduced ability of muscle to maintain force may be related to accumulating $\mathrm{H}^{+}$. However, in a recent special communication, Westerblad ${ }^{5}$ suggested that while temporal correlations between change in intracellular $\mathrm{pH}$ and decrease in muscle force have been observed, recovery of force in the absence of $\mathrm{pH}$ recovery has been observed.

Intermittent high-intensity exercise decreases blood and muscle $\mathrm{pH}$, ostensibly contributing to skeletal muscle fatigue. ${ }^{3}$ Repeated high-intensity exercise performance therefore depends largely upon metabolic buffering capacity. ${ }^{6}$ Sodium bicarbonate $\left(\mathrm{NaHCO}_{3}^{-}\right)$is an ergogenic aid, employed by athletes prior to exercise, to increase 
buffering capacity of $\mathrm{H}^{+}$ions, in an attempt to delay fatigue. ${ }^{7}$ While muscle cell membranes are impervious to $\mathrm{HCO}_{3}^{-}$, increasing extracellular $\mathrm{HCO}_{3}^{-}$increases the $\mathrm{pH}$ gradient between intracellular and extracellular environments. ${ }^{8}$ As a result, significantly higher blood lactate concentrations [BLa] have been observed following $\mathrm{NaHCO}_{3}^{-}$supplementation, ${ }^{9}$ suggesting $\mathrm{NaHCO}_{3}^{-}$increases the efflux of $\mathrm{H}^{+}$and $\mathrm{La}^{-}$from working muscle into general circulation. As such, during specific exercise protocols (those involving a large anaerobic component), $\mathrm{NaHCO}_{3}^{-}$may be efficacious in enhancing exercise performance. ${ }^{10}$

Lavender and Bird ${ }^{11}$ reported that peak power output during 10 -sec sprints on a cycle ergometer was significantly greater following $\mathrm{NaHCO}_{3}^{-}$ingestion compared to a placebo. Yet Vanhatalo et al ${ }^{12}$ observed that despite pre-exercise alkalosis being achieved by $\mathrm{NaHCO}_{3}^{-}$ingestion, critical power, work done above the critical power ( $W^{\prime}$ : considered as energy available from anaerobic sources), and total work done during a 3-min all-out test were unaltered. However, performance enhancement has been demonstrated during repeated sprint swimming, ${ }^{13}$ and high-intensity running ${ }^{14}$ was preceded by $\mathrm{NaHCO}_{3}^{-}$ingestion. Moreover, some authors have reported improved performance during the Yo-Yo intermittent recovery test 2 (IR2). ${ }^{15,16}$ However, some ambiguity remains regarding the effectiveness of $\mathrm{NaHCO}_{3}{ }^{-}$ingestion prior to the Yo-Yo test. $^{17}$

Given that numerous sporting events are characterized by repeated periods of intense anaerobic activity, ${ }^{18,19}$ tolerance to repeated bouts of intense exercise is necessary. As proposed by Bangsbo et al, ${ }^{18}$ the Yo-Yo IR1 appears well suited to this purpose. The test is conducted to volitional exhaustion, or an inability to maintain running speed. Repeated sprints of progressively increasing velocities are required, interspersed with $10 \mathrm{sec}$ of active recovery. This test has been proposed as an estimation of match-related fitness in handball, ${ }^{20}$ soccer, ${ }^{21}$ and rugby league. ${ }^{22}$

While the influence of $\mathrm{NaHCO}_{3}{ }^{-}$during the Yo-Yo IR2 is well characterized, ${ }^{15,16}$ there remains a paucity of data concerning the effect of $\mathrm{NaHCO}_{3}{ }^{-}$ingestion prior to the Yo-Yo IR1. Therefore, the aim of the present investigation was to examine the influence of acute $\mathrm{NaHCO}_{3}^{-}$ingestion on [BLa], rating of perceived exertion (RPE), and performance during the Yo-Yo IR1.

\section{Methods}

\section{Participants}

In a randomized, single-blinded, repeated measures crossover design, participants reported to the laboratory following familiarization on two separate occasions, separated by $1 \mathrm{wk}$ with a 7-day washout period considered sufficient to ameliorate the residual effects of $\mathrm{NaHCO}_{3}{ }^{-14} \cdot{ }^{14}$ Testing was completed at the same time of day (19:00-20:00 h) to abrogate the influence of diurnal variation in exercise performance. ${ }^{23}$

Prior to enrollment, participants completed a physical activity readiness questionnaire and provided written informed consent. The investigation was approved by the London Metropolitan University Research Ethics Committee. An a priori power calculation using mean \pm standard deviation (SD) from previous literature ${ }^{15}$ suggested a sample size of $\mathrm{N}=6$ would be adequate to obtain statistical power of 0.8 for a two-tailed test. Therefore, to allow for dropouts, eight recreationally active males (age: $26 \pm 4 \mathrm{yr}$, body height: $178 \pm 6 \mathrm{~cm}$, body mass: $82 \pm 10 \mathrm{~kg}$ ) volunteered to participate in the study. Participants had abstained from exercise and alcohol for the previous $24 \mathrm{~h}$.

\section{Experimental procedures}

Participants arrived at the laboratory 3-4 h postprandial; thereafter body height (Seca Leicester Height Measurer; Birmingham, UK) and mass (Salter Touch Analyser Digital Scales; Kent, UK) were recorded. On each occasion, [BLa] concentration was measured at rest and postexercise, using a handheld portable analyzer measuring whole blood (LactatePro 2; Arkray, Kyoto, Japan). Following piercing of the skin using a retractable lancet, a $0.3-\mu \mathrm{L}$ blood sample was obtained from the fingertip and drawn directly from the sample site into the coded reagent strips of the device. This method has demonstrated interclass correlations (ICCs) of 0.989. ${ }^{24}$ Following resting samples, participants consumed a $500 \mathrm{~mL}$, sugar-free beverage containing either 1) $0.3 \mathrm{~g} \cdot \mathrm{kg}^{-1}$ body weight $\mathrm{NaHCO}_{3}{ }^{-}$or 2) an equimolar amount of the placebo, sodium chloride. This dosage strategy has previously been used by Higgins et al. ${ }^{25}$ Sodium chloride was consumed to ensure participants' inability to identify the $\mathrm{NaHCO}_{3}^{-}$solution, as previously demonstrated. ${ }^{14}$

\section{Yo-Yo IR I}

Sixty minutes postingestion, participants completed a standardized 5-min warm-up involving walking at a self-selected pace, interspersed with two 5- to 10-sec all-out sprints. A recovery period of 2 min was permitted between warm-up and test. The Yo-Yo IR1 requires participants to perform $2 \times 20 \mathrm{~m}$ shuttle runs at speeds indicated by beeps on an audio recording, interspersed by 10 -sec active recovery, $5 \mathrm{~m}$ behind the starting marker. Participants performed the Yo-Yo IR1 until volitional exhaustion, or when participants 
were incapable of maintaining the designated running speed. On the first occasion, participants were unable to maintain the designated running speed, a warning was given from the researcher, and on the second time, participants were withdrawn from the test. When individuals twice failed to reach the finishing line in the time allocated, or reached volitional exhaustion, cumulative time (sec) was recorded. Following test completion, $\mathrm{RPE}^{26}$ were recorded within 30 $\mathrm{sec}$, and [BLa] concentrations were collected within $2 \mathrm{~min}$. The Yo-Yo IR1 has demonstrated reliability and validity in measurement of match-related fitness,$^{20}$ capable of distinguishing between competition level, playing position, and training adaptation. ${ }^{27} \mathrm{~A}$ recent investigation observed ICCs of $0.82-0.92 .^{28}$

\section{Statistical analysis}

Data were analyzed using SPSS (version 22; IBM North America, New York, NY, USA). To determine parametricity, Levene's tests (homogeneity of variance) and Shapiro-Wilk (normal distribution) were employed. Where parametric assumptions were met, data were analyzed using a paired samples $t$-test to examine differences in Yo-Yo IR1 performance between conditions. A $2 \times 2$ (time point $\times$ condition) repeated measures analysis of variance (ANOVA) was used to test for differences in [BLa], and a Wilcoxon signed rank test was used to examine differences between conditions for RPE. In all instances, significance was set a priori at $p<0.05$, and effect size is reported for primary outcome measures. Effect sizes are reported as eta squared $\left(\eta^{2}\right)$ in instances with more than one comparison, and Cohen's $d$ for paired comparisons. Effect sizes are considered trivial $(<0.2)$, small $(0.2-0.49)$, medium (0.5-0.79), or large $(\geq 0.8) .{ }^{29}$ Data are presented as mean \pm SD in all instances.

\section{Results}

Due to $100 \%$ adherence, eight participants $(\mathrm{N}=8)$ completed both conditions, and statistical power was confirmed as 0.981 for cumulative time. Paired samples $t$-test revealed significantly improved Yo-Yo IR1 under the $\mathrm{NaHCO}_{3}^{-}$condition compared to placebo $(610 \pm 267 \mathrm{sec}$ and $556 \pm 259$ sec, respectively: $p=0.01$; Cohen's $d=0.20$ [Figure 1A]). Postexercise RPE was not significantly different $(p=1.00)$ between $\mathrm{NaHCO}_{3}^{-}$and placebo conditions $(16 \pm 2$ and $16 \pm 1$ for $\mathrm{NaHCO}_{3}^{-}$and placebo, respectively [Figure 1B]).

$\mathrm{NaHCO}_{3}{ }^{-}$and placebo pretest [BLa] were not significantly different $(p=0.209)$. A significant, large effect of time point $\left(p=0.002 ; \eta^{2}=0.758\right)$ and condition $(p<0.001$; $\left.\eta^{2}=0.900\right)$ was observed for [BLa] (Figure 2). Moreover, a significant, large interaction effect $\left(p=0.001 ; \eta^{2}=0.824\right)$
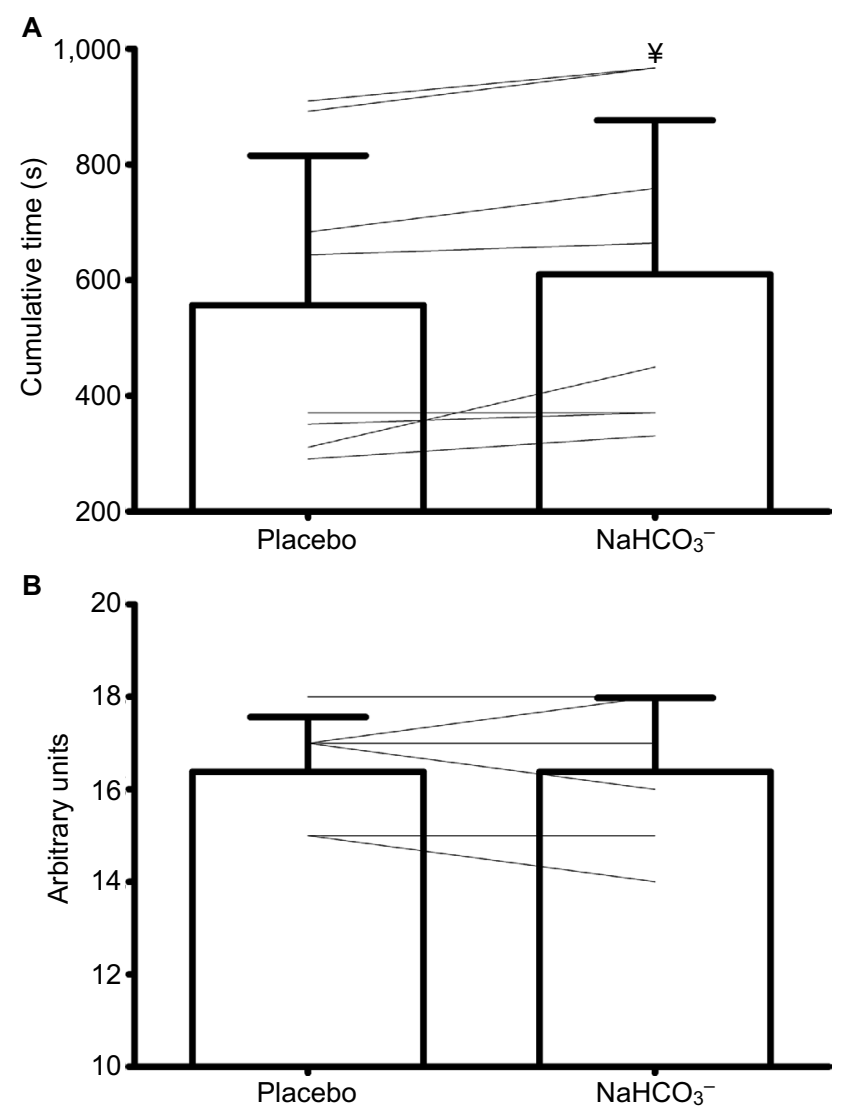

Figure I Performance and RPE during the $\mathrm{Yo}_{\mathrm{O}} \mathrm{YO} \mathrm{IRI}$ following $\mathrm{NaHCO}_{3}{ }^{-}$ingestion. Notes: (A) Cumulative time completed and (B) rating of perceived exertion, during the Yo-Yo IRI in a group of recreationally active males $(n=8)$ following sodium bicarbonate $\left(\mathrm{NaHCO}_{3}^{-}\right)$or placebo ingestion. Data are presented as individual lines and mean $\pm S D$. $¥$ denotes significantly increased compared to placebo $(p=0.0 \mathrm{I})$. Abbreviations: IRI, intermittent recovery test I; SD, standard deviation.

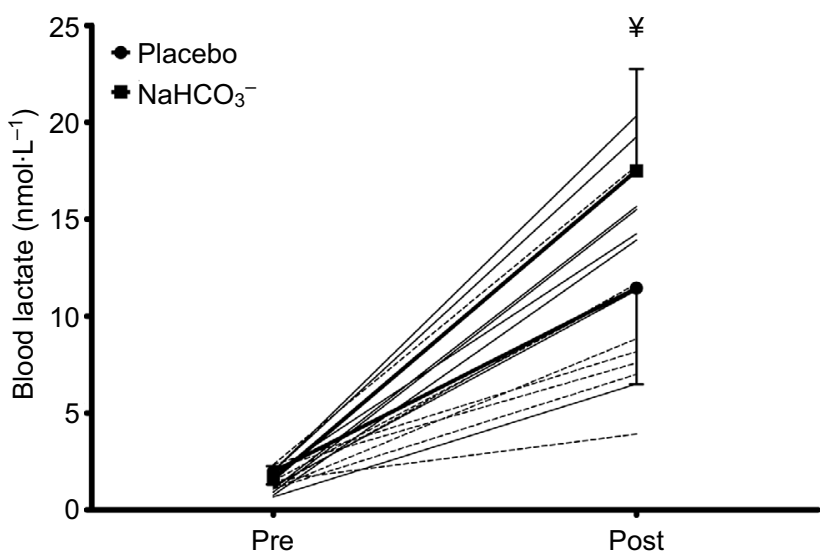

Figure 2 Blood lactate concentrations samples pre- and post-Yo-Yo intermittent recovery test $I$ in a group of recreationally active males $(n=8)$ following sodium bicarbonate $\left(\mathrm{NaHCO}_{3}^{-}\right)$or placebo ingestion.

Notes: Data are presented as individual lines and mean \pm SD. Dashed lines represent individual response to placebo, whereas solid lines represent individual response to $\mathrm{NaHCO}_{3}^{-}$. $¥$ denotes significantly increased compared to placebo $(p<0.0 \mathrm{I})$.

Abbreviation: SD, standard deviation.

was detected. Blood lactate increased more under $\mathrm{NaHCO}_{3}$ (1.6 \pm 0.7 to $17.5 \pm 5.2 \mathrm{mmol} \cdot \mathrm{L}^{-1} ; p<0.001$; Cohen's $d=4.29$ ) compared to placebo $\left(2.0 \pm 0.7\right.$ to $11.5 \pm 5.0 \mathrm{mmol} \cdot \mathrm{L}^{-1}$; $p=0.001$; Cohen's $d=2.66$ ). 


\section{Discussion}

The present study examined the effects of acute $\mathrm{NaHCO}_{3}^{-}$ ingestion on Yo-Yo IR1 performance, [BLa], and RPE. The primary finding of this investigation was that acute supplementation of $\mathrm{NaHCO}_{3}^{-}$improved Yo-Yo IR1 performance. Moreover, greater [BLa] was observed postexercise under the $\mathrm{NaHCO}_{3}^{-}$condition compared to placebo.

The present study is in line with previous investigations in reporting a $52 \%$ increase in [BLa] following $\mathrm{NaHCO}_{3}^{-}$ingestion compared to placebo. Bishop and Claudius ${ }^{14}$ reported [BLa] increased $26 \%$ following $\mathrm{NaHCO}_{3}{ }^{-}$ingestion. Differences in the magnitude of [BLa] increase may be explicated by dissimilar exercise protocols, as the present investigation examined the influence of $\mathrm{NaHCO}_{3}^{-}$ingestion on Yo-Yo IR1 performance, whereas the study by Bishop and Claudius ${ }^{14}$ investigated the effect during intermittent sprint cycling.

Substantial research exists examining the ergogenic effect of $\mathrm{NaHCO}_{3}^{-}$on exercise performance. ${ }^{6,30,31}$ In a double-blinded, crossover study, Hobson et a ${ }^{31}$ examined the performance of 20 male rowers undertaking two 2,000 $\mathrm{m}$ rowing time trials, and reported $0.3 \mathrm{~g} \cdot \mathrm{kg}^{-1} \mathrm{NaHCO}_{3}^{-}$ enhanced rowing performance, particularly in the final $500 \mathrm{~m}$ (by $1.1 \pm 1.7 \mathrm{sec}$ ). Likewise, Higgins et a ${ }^{25}$ reported $\mathrm{NaHCO}_{3}^{-}$ingestion increased cycling capacity by $17 \%$ at $100 \%$ power output determined using a 3-min stageramp protocol, although not at $110 \%$ or $120 \%$, suggesting $\mathrm{NaHCO}_{3}^{-}$ingestion significantly improves continuous constant load cycling at $100 \%$ peak minute power, but not at $110 \%$ or $120 \%$. Goldfinch et al ${ }^{32}$ similarly reported six male athletes ran $400 \mathrm{~m}$ significantly faster following $0.4 \mathrm{~g} \cdot \mathrm{kg}^{-1}$ body weight $\mathrm{NaHCO}_{3}{ }^{-}$compared to placebo ( $56.94 \pm 2.25 \mathrm{sec}$ vs $58.63 \pm 2.25 \mathrm{sec}$ for $\mathrm{NaHCO}_{3}{ }^{-}$and placebo, respectively).

Recently, $\mathrm{NaHCO}_{3}^{-}$supplementation has garnered interest in relation to intermittent sprint performance, as this modality is more representative of sprint profiles of team sports. ${ }^{33}$ Glaister ${ }^{33}$ suggested the ability to repeat maximal, short-duration sprint efforts, while resisting fatigue is a determining factor in many team sports. Although mean heart rate and oxygen uptake $\left(\mathrm{VO}_{2}\right)$ during team sports are approximately $80 \%$ and $70 \%$ maximum, respectively, ${ }^{34-36}$ expressing intensity as an average during these events belies the complexity of physiological processes. For example, in soccer, high-intensity movements typically last $\sim 4 \mathrm{sec}$, and $\sim 22 \mathrm{~m}$, although this is position dependent. ${ }^{37}$ Despite the intricacies of determining intensity of repeated sprints during match play, it is evident that repeated sprint ability is a key determinant of field-based team sports, ${ }^{38}$ and therefore strategies to improve this ability via ergogenic aids are of interest to practitioners and athletes alike.

The present investigation reports a $9.7 \%$ improvement in Yo-Yo IR1 performance in a group of recreationally active males and is therefore in line with previous research in suggesting $\mathrm{NaHCO}_{3}^{-}$ingestion improves intermittent exercise performance. ${ }^{31}$ Krustrup et al ${ }^{15}$ reported a $14 \%$ improvement in the Yo-Yo IR2 as a result of $\mathrm{NaHCO}_{3}^{-}$ingestion in a group of trained athletes. Data from the same laboratory suggest that when preceded by intense arm cranking exercise, $\mathrm{NaHCO}_{3}^{-}$ ingestion improved performance in the Yo-Yo IR2 by $23 \%$ compared to placebo. ${ }^{16}$

\section{Conclusion}

The present study demonstrates acute $\mathrm{NaHCO}_{3}^{-}$ingestion improves performance in the Yo-Yo IR1 without concomitant change in perception of effort. One limitation of the present study is that we did not measure blood gas parameters, which would add confirmatory evidence that the performance enhancement observed was a result of $\mathrm{NaHCO}_{3}^{-}$ingestion. However, given the design of our investigation (randomized crossover), and increased [BLa], we find it difficult to provide an alternative explanation. As such, the current study is the first to observe increased performance during the Yo-Yo IR1 following $\mathrm{NaHCO}_{3}^{-}$ingestion, which adds to the body of literature supporting the ergogenic effect of $\mathrm{NaHCO}_{3}{ }^{-}$on intermittent sprint exercise.

\section{Disclosure}

The authors report no conflicts of interest in this work.

\section{References}

1. Allen DG, Lannergren J, Westerblad H. Muscle cell function during prolonged activity: cellular mechanisms of fatigue. Exp Physiol. 2005; 80:497-527.

2. Robergs R, Hutchinson K, Hendee S, Madden S, Siegler J. Influence of pre-exercise acidosis and alkalosis on the kinetics of acid-base recovery following intense exercise. Int J Sport Nutr Exerc Metab. 2005;15:59-74.

3. Fitts RH. Cellular mechanisms of muscle fatigue. Physiol Rev. 1994; 74:49-94.

4. Gladden B. Lactate metabolism: a new paradigm for the third millennium. J Physiol. 2004;58:5-30.

5. Westerblad H. Acidosis is not a significant cause of skeletal muscle fatigue. Med Sci Sport Exerc. 2016;48:2339-2342.

6. Siegler JC, Gleadall-Sidall DO. Sodium bicarbonate ingestion and repeated swim sprint performance. J Strength Cond Res. 2010;24:3105-3111.

7. Cameron SL, McLay-Cooke RT, Brown RC, Gray AR, Fairbairn KA. Increased blood $\mathrm{pH}$ but not performance with sodium bicarbonate supplementation in elite rugby union players. Int J Sport Nutr Exerc Metab. 2010;20:307-321.

8. McNaughton LR, Siegler J, Midgley A. Ergogenic effects of sodium bicarbonate. Curr Sports Med Rep. 2008;7:230-236.

9. Linderman J, Fahey TD. Sodium bicarbonate ingestion and exercise performance: an update. Sports Med. 1991;11:71-77. 
10. Matson LG, Tran ZV. Effect of sodium bicarbonate ingestion on anaerobic performance: a meta-analytic review. Int J Sport Nutr. 1993;3:2-28.

11. Lavender G, Bird SR. Effect of sodium bicarbonate ingestion upon repeated sprints. Br J Sports Med. 1989;23:41-45.

12. Vanhatalo A, McNaughton LR, Siegler J, Jones AM. Effect of induced alkalosis on the power-duration relationship of "all-out" exercise. Med Sci Sports Exerc. 2010;42:563-570.

13. Lindh AM, Peyrebrune MC, Ingham SA, Bailey DM, Folland JP. Sodium bicarbonate improves swimming performance. Int J Sports Med. 2008;29:519-523.

14. Bishop D, Claudius B. Effects of induced metabolic alkalosis on prolonged intermittent sprint performance. Med Sci Sport Exerc. 2005; 37:757-767.

15. Krustrup P, Ermidis G, Mohr M. Sodium bicarbonate intake improves high-intensity intermittent exercise performance in trained young men. J Int Soc Sports Nutr. 2015;12:25.

16. Marriot M, Krustrup P, Mohr M. Ergogenic effects of caffeine and sodium bicarbonate supplementation on intermittent exercise performance preceded by intense arm cranking exercise. J Int Soc Sports Nutr 2015;12:13.

17. Karavelioglu MB. Detection of the effects of sodium bicarbonate supplement on blood lactate and heart rate values of female futsal players before and after Yo-Yo/1 Test. Anthropologist. 2014;18:745-749.

18. Bangsbo J, Norregaard L, Thorso F. Activity profile of competition soccer. Can J Sport Sci. 1991;16:110-116.

19. Manchado C, Tortosa-Martinez J, Vila H, Ferragut C, Platen P. Performance factors in women's team handball: physical and physiological aspects - a review. J Strength Cond Res. 2013;27:1708-1719.

20. Souhail H, Castagna C, Mohamed HY, Younes H, Chamari K. Direct validity of the yo-yo intermittent recovery test in young team handball players. J Strength Cond Res. 2010;24:465-470.

21. Rampinini E, Sassi A, Azzalin A, et al. Physiological determinants of Yo-Yo intermittent recovery tests in male soccer players. Eur J Appl Physiol. 2010;108;401-409.

22. Atkins SJ. Performance of the Yo-Yo Intermittent Recovery Test by elite professional and semi-professional rugby league players. $J$ Strength Cond Res. 2006;20:222-225.

23. Hayes LD, Bickerstaff GF, Baker JS. Interactions of cortisol, testosterone, and resistance training: influence of circadian rhythms. Chronobiol Int. 2010;27:675-705.
24. Tanner RK, Fuller KL, Ross ML. Evaluation of three portable blood lactate analysers: Lactate Pro, Lactate Scout and Lactate Plus. Eur J Appl Physiol. 2010;109:551-559.

25. Higgins MF, James RS, Price MJ. The effects of sodium bicarbonate $\left(\mathrm{NaHCO}_{3}^{-}\right)$ingestion on high intensity cycling capacity. J Sport Sci. 2013; 31:972-981.

26. Borg GA. Psychophysical bases of perceived exertion. Med Sci Sport Exerc. 1982;14:377-381.

27. Bangsbo J, Iaia FM, Krustrup P. The Yo-Yo Intermittent Recovery Test: a useful tool for evaluation of physical performance in intermittent sports. Sports Med. 2008;38:37-51.

28. Deprez D, Coutts AJ, Lenoir M, et al. Reliability and validity of the Yo-Yo intermittent recovery test level 1 in young soccer players. J Sport Sci. 2014;32:903-910.

29. Cohen J. Statistical Power Analysis for the Behavioral Sciences. 2nd ed. Hillsdale, NJ: Lawrence Earlbaum Associates; 1988.

30. Artioli GG, Gualano B, Coelho DF, Benatti FB, Gailey AW, Lancha AH Jr. Does sodium bicarbonate ingestion improve simulated judo performance? Int J Sport Nutr Exerc Metab. 2007;17:206-217.

31. Hobson RM, Harris RC, Martin D, et al. Effect of sodium bicarbonate supplementation on 2000-m rowing performance. Int J Sports Physiol Perf. 2014;9:139-144.

32. Goldfinch J, McNaughton L, Davies P. Induced metabolic alkalosis and its effects on 400-m racing time. Eur J Appl Physiol. 1988;57: 45-48.

33. Glaister M. Multiple sprint work: physiological responses, mechanisms of fatigue, and the influence of aerobic fitness. Sports Med. 2005;35: 757-777.

34. Christmas MA, Richmond SE, Cable NT, Arthur PG, Hartmann PE. Exercise intensity and metabolic response in singles tennis. J Sport Sci. 1998;16:739-747.

35. Faccini P, Dal Monte A. Physiologic demands of badminton match play. Am J Sports Med. 1996;24:S64-S66.

36. Liddle SD, Murphy MH, Bleakley W. A comparison of heart rate responses in racquet games. J Hum Mov Stud. 1996;30:159-176.

37. Withers RT, Maricic Z, Wasilewski S, Kelly L. Match analyses of Australian professional soccer players. J Hum Mov Stud. 1982;8:159-176.

38. Spencer M, Bishop D, Dawson B, Goodman C. Physiological and metabolic responses of repeated-sprint activities: specific to field-based team sports. Sports Med. 2005;35:1025-1044.
Nutrition and Dietary Supplements

\section{Publish your work in this journal}

Nutrition and Dietary Supplements is an international, peer-reviewed, open access journal focusing on research into nutritional requirements in health and disease, impact on metabolism and the identification and optimal use of dietary strategies and supplements necessary for normal growth and development. The journal welcomes submitted papers covering original research, basic science,

\section{Dovepress}

clinical \& epidemiological studies, reviews and evaluations, guidelines, expert opinion and commentary, case reports and extended reports. The manuscript management system is completely online and includes a very quick and fair peer-review system, which is all easy to use. Visit http://www.dovepress.com/ testimonials.php to read real quotes from published authors. 